\title{
Traumatic spinal cord injuries in Istanbul, Turkey. An epidemiological study
}

\author{
ŞS Karamehmetoğlu ${ }^{1}$, Ş Ünal ${ }^{2}$, İ Karacan ${ }^{2}, \mathrm{H}_{\text {Yílmaz }}{ }^{3}$, HŞ Togay ${ }^{4}, \mathrm{M} \mathrm{Ertekin}^{5}, \mathrm{M} \mathrm{Döşoğlu}^{6}, \mathrm{MI} \mathrm{Ziyal}^{7}$, \\ D Kasaroğlu ${ }^{8}$ and T Hakan ${ }^{9}$ \\ ${ }^{1}$ Assistant Professor, ${ }^{2}$ Resident, Department of Physical Medicine and Rehabilitation, Cerrahpaşa Medical \\ Faculty, Istanbul University; ${ }^{3}$ Physiatrist, Istanbul Rehabilitation Centre; ${ }^{4}$ Resident, Neurosurgery Department, \\ Okmeydani SSK Hospital; ${ }^{5}$ Physiatrist, PMR Department, Kartal SSK Hospital; ${ }^{6}$ Resident, Neurosurgery \\ Department, Haydarpaşa State Hospital; ${ }^{7}$ Resident, Neurosurgery Department, Şişli Etfal State Hospital; \\ ${ }^{8}$ Resident, Neurosurgery Department, Kartal State Hospital; ${ }^{9}$ Resident, Neurosurgery Department, Taksim State \\ Hospital, Turkey
}

This is a retrospective study conducted in all of the hospitals of Istanbul to survey new patients with a traumatic spinal cord injury (SCI) in 1992. In that year 152 new traumatic SCI were identified. The estimated annual incidence was 21 per million population. The male/female ratio was $3 / 1$. The mean age was 33 , being 34 for male patients and 31 for female patients. $72 \%$ of all patients were under the age of forty. The major causes of SCI were falls $(43 \%)$ and car accidents $(41 \%)$, followed by being struck by an object $(7 \%)$, gunshot injury (5\%), stab injury (2\%). Fifty patients $(33 \%)$ were tetraplegic and $102(67 \%)$ paraplegic. Regarding the tetraplegic patients the commonest level was $\mathrm{C} 5$, in those who were paraplegic L1. There were no cases at levels $\mathrm{C} 1, \mathrm{~T} 1$ or $\mathrm{T} 2$. The commonest associated injury was head trauma, followed by fractures of an extremity (or extremities). Severe head trauma, as a major cause of death, may obscure the actual incidence of SCI in this study. Accidental falls (exceeding road accidents) were mostly due to falls from buildings and accidents on work premises.

Keywords: spinal cord injury (SCI); epidemiology; incidence; Istanbul; Turkey

\section{Introduction}

At present there is no epidemiological study of SCI in Turkey, thus we do not know the actual dimensions of this serious and disabling condition. Furthermore there is no national SCI registry system.

Istanbul is the most populated city in Turkey, located in western Turkey on both sides of the Bosphorus which is a natural border between Europe and Asia. The population of İstanbul was 7309190 in $1992 .{ }^{1}$ We aimed to find out the incidence of traumatic SCI in Istanbul.

Materials and methods

We conducted this study from 1 January 1992 to 31 December 1992, retrospectively, in all the hospitals of Istanbul. Records of SCI patients were obtained from the emergency services, intensive care units and departments of orthopaedic surgery, neurosurgery and rehabilitation medicine. Patients who died before reaching hospital were excluded if it was not known if they had a SCI.

\section{Results}

Incidence

In this study, 152 SCI patients were registered from 1 January 1992 to 31 December 1992. As the population of Istanbul was 7309190 the annual incidence of traumatic SCI in Istanbul was 21 per million population.

\section{Gender and age}

There were 115 males and 37 females with SCI, the male/female ratio being 3/1. The mean age was 33 , being 34 for male patients and 31 for females. SCI was most prevalent between 20 and 29 years inclusive with only one peak in this age group (Figure 1). But when we considered the incidence by age groups, although there was still some preponderance of the same age

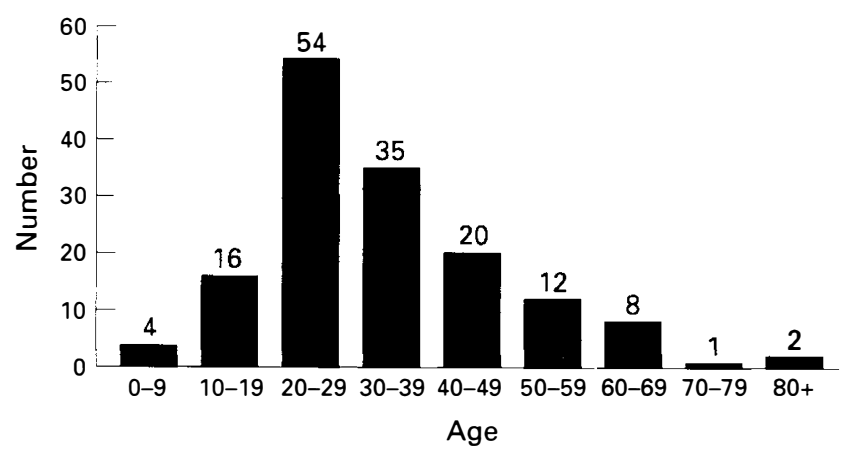

Figure 1 Age distribution at the time of SCI 
groups they did not differ much until the 70-79 age group. And after the age of 80 there was a dramatic increase in the incidence because of the very small number of people in this age group (Figure 2).

\section{Causes of SCI}

In this study, falls exceeded road accidents as a cause of SCI. Falls and road accidents together accounted for $83 \%$ of all causes. Other causes were being struck by an object $(7 \%)$, gunshot injury $(5 \%)$, stab injury $(2 \%)$. Falls were mostly falls from buildings and accidents in the workplace, and were more prominent in younger age groups and older age groups; but road accidents were more prominent in the middle age groups. Motorcycle accidents accounted for $3.3 \%$ of all road accidents, because of the small number of motorcycles compared to cars.

\section{Seasonal distribution}

The seasonal distribution of SCI was prominent in spring with falls as a major cause. In summer, road accidents were the main cause (Figure 3 ).

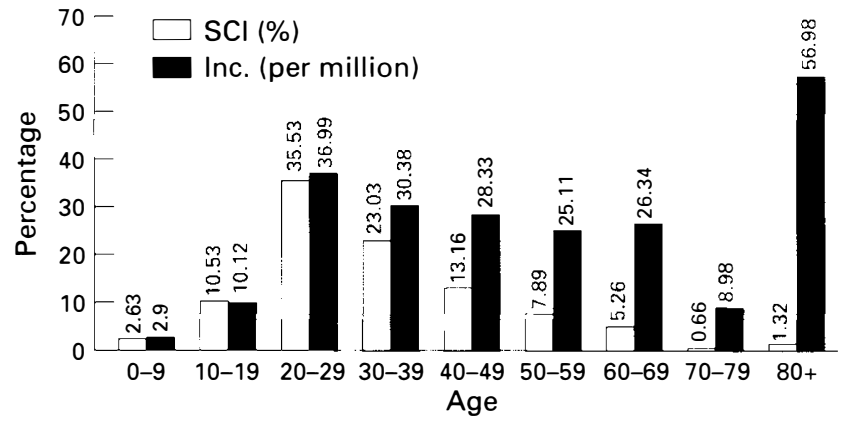

Figure 2 Incidence and distribution of SCI by age groups

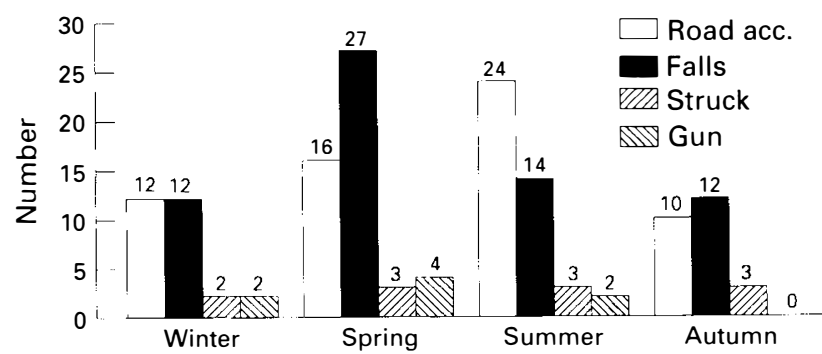

Figure 3 Causes and seasonal distribution in SCI

\section{Associated trauma}

In more than $77 \%$ of patients with SCI there was no associated trauma. The commonest associated trauma was head trauma, followed by extremity fractures, burns, pneumothorax and others.

\section{Discussion}

When we compared the incidence of SCI in the literature, we saw that it ranged from 6 to 56.1 per million population. ${ }^{2-11}$ (Figure 4$)$. We also saw that there were considerable differences within one country eg USA and Taiwan. This might be due to methodological, demographic, sociological, geographical and political factors. The incidence of SCI in Istanbul ranged somewhere between European and Asian countries; we require to standardize this kind of epidemiological studies at least methodologically.

As in most of the studies, SCI was most often seen in the 20-29 age group. In Turkey, the population is very young and the 20-29 age group is the most prominent. As this period of life is characterized by high risk activities such as driving, it appears normal to have the highest incidence of SCI in this age group. When we considered the incidence by age groups we found the

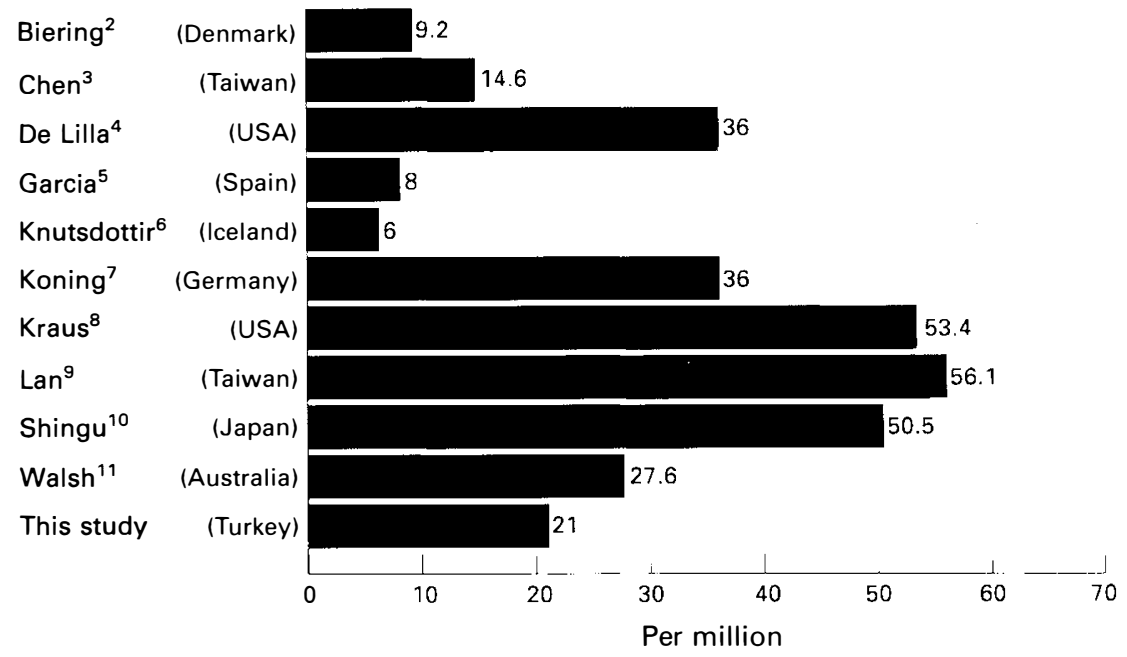

Figure 4 Incidence of SCI in literature 
highest incidence after the age of 80 (56.98 per million). There was a similar finding in Knutsdottir's report and in a Japanese study. ${ }^{10}$ This dramatic increase with old age may be due to the lower ratio of this age group in the population, or to the instability of the vertebral column due to degenerative diseases, ligamanteous laxity, osteoporosis etc. If the incidence by age groups was reported in the other studies, it would be possible to expect the same result.

Although there was near equality in number between males and females in the population, male patients with SCI tripled females as is reported in most of the studies in the literature. ${ }^{5,6}$ When we considered the incidence by gender, it was also three times greater in males. Being male appeared as an important risk factor for SCI, because in a developing country like Turkey men are the bread winners. They work outside in risky situations such as on high buildings and in unprotected places, and they drive cars. On the other hand women are usually at home as housewives so they are protected from the risks of living outside.

Most of the patients with SCI were married, but marriage did not appear as a risk factor when we considered the incidence of the three groups with SCI (married, single, widow).

Head trauma as a common cause of death might obscure the actual incidence of SCI. It was estimated that $12-25 \%$ of deaths at the time of admission to hospital were associated with SCI. ${ }^{12.13}$

This study differed from other studies in that falls exceeded road accidents as a cause of SCI. In all of the literature road accidents were the major cause of SCI. ${ }^{1-5,14}$ SCI due to falls appeared as a feature in developing countries. ${ }^{15,16}$ According to the official data $^{17} 2 \%$ of the population in İstanbul owned registered motorcycles. Ten per cent owned cars. The risk of SCI for motorcyclists was double that for the car drivers. In Huallien, where there are 490 motorcycles per thousand, this risk was higher. ${ }^{9}$ Falls and road accidents were the leading causes, accounting for $83 \%$ of SCI, and these two causes had more or less the same percentage incidence in the literature. Therefore it would be logical, especially for developing countries, to consider this fact in preventive programmes.

\section{References}

1 State Institute of Statistics Prime Ministry, Republic of Turkey. Statistical Year-book of Turkey, 1992.

2 Biering-Sørensen F, Pedersen V, Clausen S. Epidemiology of spinal cord lesions in Denmark. Paraplegia 1990; 28: 105-118.

3 Chen CF, Lien IN. Spinal cord injuries in Taipei, Taiwan 1978-81. Paraplegia 1985; 23: 364-370.

4 De Lilla T, Eddy S, Cooper T, Hensley K. Five year summary on spinal cord injuries statistics, Florida, 1990.

5 Garcia-Renses J, Herruzo-Cabrera R, Martinez-Moreno M. Epidemiological study of spinal cord injury in Spain 1984-1985. Paraplegia 1991; 28: 180-190.

6 Knutsdottir S. Spinal cord injuries in Iceland 1973-1989. A follow up study. Paraplegia 1993; 31: 68-72.

7 Koning W, Frowein RA. Incidence of spinal cord injuries in the Federal Republic of Germany. Neurosurg Rev 1989; 12: 562-566.

8 Kraus JF et al. Incidence of traumatic spinal cord lesions. J Chron Dis 1975; 28: 471-492.

9 Lan C et al. Traumatic spinal cord injuries in the rural region of Taiwan: an epidemiological study in Hualien country, 1986-1990. Paraplegia 1993; 31: 398-403.

10 Shingu H, Ikata T, Katoh S, Akatsu T. Spinal cord injuries in Japan: a nationwide epidemiological survey in 1990. Paraplegia 1994; 32: 3-8.

11 Walsh JE. Costs of spinal cord injury in Australia. Paraplegia 1988; 26: 386-388.

12 Wilmot CB, Cope DN, Hall KM, Acker M. Occult head injury: its incidence in spinal cord injury. Arch Phys Med Rehabil 1985; 66: 227-231.

13 Davidoff $\mathrm{G}$ et al. Closed head injury in acute traumatic spinal cord injury: incidence and risk factors. Arch Phys Med Rehabil 1988; 69: 869-872.

14 Tator $\mathrm{CH}$ et al. Changes in epidemiology of spinal cord injury from 1947 to 1981. Surg Neurol 1993; 40: 207-215.

15 Marshall A, Chahal AS, Fraks MS, Chabbra HS. Pattern of spinal cord injuries in Delhi. 33rd Annual Scientific Meeting of the International Medical Society of Paraplegia, 30 May-2 June 1994, Kobe, Japan. (Abstract 57).

16 Silberstein B, Rabinovic S. Epidemiology of spinal cord injuries in Novosibirsk in Delhi. 33rd Annual Scientific Meeting of the International Medical Society of Paraplegia, 30 May-2 June 1994, Kobe, Japan. (Abstract 149).

17 State Institute of Statistics Prime Ministry, Republic of Turkey. Summary statistics on transportation and communication, 1992. 